\title{
Electrical Conductivity, Relaxation and the Glass Transition: A New Look at a Familiar Phenomenon
}

Paul W. Angel

Lewis Research Center

Cleveland, Ohio

Mark R. DeGuire and Alfred R. Cooper

Case Western Reserve University

Cleveland, Ohio

Prepared for the

13th University Conference on Glass Science

sponsored by the Rensselaer Polytechnic Institute

Troy, New York, August 9-11, 1995

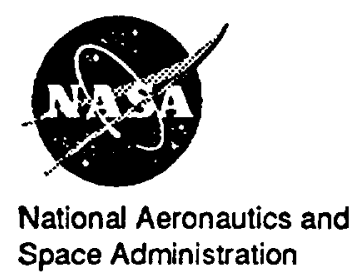




\title{
Electrical Conductivity, Relaxation and the Glass Transition: A New Look at a Familiar Phenomenon
}

\author{
Paul W. Angel ${ }^{2}$ *, Mark R. DeGuire ${ }^{b}$, Alfred R. Cooper ${ }^{b}$ \\ -NASA Lewis Research Center, Cleveland, OH 44135, USA. \\ - Department of Materials Science and Engineering, Case Western Reserve University, Cleveland, OH 44106-7204, USA.
}

\begin{abstract}
Annealed samples from a single melt of a $10 \mathrm{~mol} \% \mathrm{~K}_{2} \mathrm{O}-90 \mathrm{SiO}_{2}$ glass were reheated to temperatures ranging from 450 to $800^{\circ} \mathrm{C}$, held isothermally for $20 \mathrm{~min}$, and then quenched in either air or a silicone oil bath. The complex impedance of both the annealed and quenched samples was measured as a function of temperature from 120 to $250^{\circ} \mathrm{C}$ using ac impedance spectroscopy from $1 \mathrm{~Hz}$ to $1 \mathrm{MHz}$. The dc conductivity, $\sigma_{\mathrm{dc}}$, was measured from the low frequency intercept of depressed semicircle fits to the complex impedance data. When the $\sigma_{d c}$ at $150^{\circ} \mathrm{C}$ was plotted against soak temperature, the results fell into three separate regions that are explained in terms of the glass structural relaxation time, $\tau$, . This $\sigma_{d c}$ plot provides a new way to look at the glass transition range, $\Delta \mathrm{T}_{\mathrm{r}}$. In addition, $\sigma_{d c}$ was measured for different soak times at $550^{\circ} \mathrm{C}$, from which an average relaxation time of $7.3 \mathrm{~min}$ was calculated. It was found that the size and position of the $\Delta T_{r}$ is controlled by both the soak time and cooling rate.
\end{abstract}

* Corresponding author. Tel: +1-216-433-8008. Telefax: +1-216-433-5544. E-mail: msange@hyperthink.lerc.nasa.gov.

\section{Introduction}

Under isobaric conditions, there are two primary factors that affect the structure of a glass. The first is the glass composition, including the water content or $\mathrm{OH}$ concentration in the glass [1]. The second is its thermal history, e.g., the rate at which the glass was cooled after melting. The equilibrium structure of a glass changes as a function of temperature [2], however it is only within the glass transition range, $\Delta T_{n}$ that the processes involved in attaining the equilibrium structure occurs at experimentally measurable time scales. Consequently, properties such as the glass density [3], index of refraction [4], dc conductivity, $\sigma_{d c},[5-8]$ and glass transition temperature [9-15] are only affected by thermal treatments within the $\Delta T_{r}$.

The $\Delta T_{r}$ is defined by an upper $\left(T_{u}\right)$ and lower $\left(T_{D}\right)$ glass transformation temperature limits. These limits are best described in terms of the glass structural relaxation time, $\tau_{8}{ }^{1}$. Above

${ }^{1}$ At any one temperature, there may be a variety of glass structural groups which would produce a distribution of relaxation times. Reference to $\tau_{1}$ in this paper will refer an average value characteristic of such a distribution of $\tau_{\mathbf{q}}$. 
$T_{w} \tau_{\varepsilon}$ is so short or the rate of internal structural change is so fast that the glass structure remains essentially in equilibrium with the instantaneous temperature of the glass. For temperatures below $T_{1}$, the $\tau_{\text {a }}$ is so long or any internal structural change occurs over such a long period of time that the glass structure is considered frozen. Within the $\Delta T_{p}$ the $\tau_{z}$ is of the order of the experimental time scale. While the glass structure is no longer considered frozen, it cannot relax quickly enough to be in equilibrium with the instantaneous temperature of the glass.

At temperatures greater than $T_{w}$, a glass losses memory of all previous structural states due to the short $\tau_{2}$ associated with these higher temperatures. Rapid quenching of a glass forming melt will cause $T_{u}$ to shift to higher temperatures. Such a glass will also have a lower density [3] (higher specific volume) than if it had been slowly cooled. Properties such as refractive index [4] and electrical resistivity [5-8], which tend to decrease with increasing specific volume, will have lower values in the quenched glass than in the slowly cooled glass. However, experimental limitations make it difficult to exceed cooling rates above $10^{6}{ }^{\circ} \mathrm{C} / \mathrm{s}$, limiting how high $T_{u}$ may be increased.

At temperatures below $T_{b}$, the time for $\tau_{a}$ becomes extremely long. It is possible to decrease either $T_{1}$ or $T_{u}$ by using slower cooling rates through the transformation range or even prolonged soaks at a constant temperature within the transformation range. However, since $\tau$, follows an Arrhenius-type dependence, one quickly reaches a practical time limit for soak time and $T_{1}$ becomes fixed since the glass structure is considered frozen below this temperature. No significant change in the glass structure can be produced by either changing the soak temperature or by varying the cooling rate, within a reasonable time scale, below $T_{1}$.

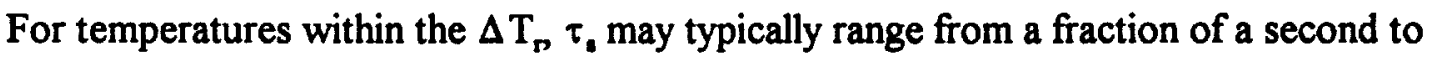
several hours. It is in this temperature region that the frozen glass structure may be altered by varying the thermal history of the glass by such means as changing the cooling rate [5] in the $\Delta T_{r}$ region. The size of $\Delta T_{r}$ can be increased by using rapid cooling rates to increase $T_{u}$ or by using extended soak times to attempt to decrease $T_{1}$. Alternatively, $\Delta T_{r}$ can be reduced if extremely slow cooling rates are used to lower $T_{u}$, causing it to approach $T_{1}$. It is far easier to adjust the $T_{u}$ 
since the cooling rate can be changed by nine orders of magnitude or more through controlled furnace cooling and rapid quenching techniques. However, the thermal history of a glass depends not only on the rate at which it was cooled, but also on the starting temperature (near the glass transition temperature) from which it was cooled, or more precisely, its state of structural relaxation at the beginning of cooling.

While the effects of composition and temperature on the conductivity of glasses have been studied extensively, thermal history effects have received much less attention $[5,6,8]$. The purpose of the present work is to explore the effects of thermal history on the electrical conductivity of a simple $10 \mathrm{~K}_{2} \mathrm{O}-90 \mathrm{SiO}_{2}$ mol\% glass. We have observed previously [8] that a fully annealed glass, when reheated to a temperature near the glass transition temperature and then quenched in air, exhibited an increase in $\sigma_{d c}$. Quenching from progressively higher temperatures increased $\sigma_{\mathrm{dc}}$ to a point, above which it was constant with increasing soak temperature. This dependency on soak temperature will be explored in more detail, as well as thermal history effects of varying both the cooling rate and the soak time that the glass remains at the soak temperature before cooling.

\section{Experimental procedure}

\subsection{Sample preparation}

Glasses were prepared in $40 \mathrm{~g}$ batches with the composition $10 \mathrm{~K}_{2} \mathrm{O}-90 \mathrm{SiO}_{2} \mathrm{~mol}_{0} \mathrm{using}$ reagent grade potassium carbonate ${ }^{2}$ and ground silica ${ }^{3}$. Each batch was dry mixed for 15 min and then calcined at $950^{\circ} \mathrm{C}$ for $4 \mathrm{~h}$ in a platinum-3\% rhodium crucible. Glasses were then melted in the same crucible using a molybdenum-disilicide furnace at $1580^{\circ} \mathrm{C}$. The glass melts were held at temperature for $6 \mathrm{~h}$ to eliminate bubbles before being placed in an annealing furnace at $550^{\circ} \mathrm{C}$ for $30 \mathrm{~min}$ and then allowed to furnace cool. Chemical analysis using flame emission spectroscopy was used to confirm potassium concentration and to determine the level of any contaminants, including alumina, soda and lithia. Alumina concentrations never exceeded $0.1 \mathrm{~mol} \%$ while alkali

\footnotetext{
${ }^{2}$ Aldrich Chemical Company, Inc., Milwaukee, WI 53233, USA.

${ }^{3}$ Fisher Scientific, Fair Lawn, NY 07410, USA.
} 
contaminants were all in the ppm level.

Low alkali content silicate glasses have been reported to phase separate given the appropriate conditions [16]. The tendency to phase separate, though, decreases with increasing atomic number of the alkalis, with lithia being the most susceptible and cesium being the least susceptible (i.e., $\mathrm{Li}>\mathrm{Na}>\mathrm{K}>\mathrm{Rb}>\mathrm{Cs}$ ) [16]. Examination of glass samples, which were all optically clear, with back scattered electron imaging in a scanning electron microscope showed no evidence of phase separation for these compositions. All glass samples were stored in a vacuum desiccator after annealing to reduce water absorption.

Specimens for electrical measurements were extracted from the crucible using a $1.6 \mathrm{~cm}$ diameter diamond coring bit yielding cylindrical samples of $1.6 \mathrm{~cm}$ in length. Cored samples were then annealed at $550^{\circ} \mathrm{C}$ for $1 \mathrm{~h}$ and cooled in the furnace at a controlled rate of $5^{\circ} \mathrm{C} / \mathrm{h}$ to $425^{\circ} \mathrm{C}$ followed by $10^{\circ} \mathrm{C} / \mathrm{h}$ to room temperature. These glasses will be referred to here-as being "fully annealed." Disks between 1.2 and $1.5 \mathrm{~mm}$ in thickness with parallel faces were cut from the annealed cores using a diamond saw. Between 6 to 8 samples were cut from each glass core.

Impedance measurements were made as described below on at least one disk from each core to confirm its repeatability with previous samples. By confirming the annealed $\sigma_{\mathrm{dc}}$ properties of each core, the possibility of other factors (e.g., contaminates or minor melt variations) accounting for dissimilarities in the measured data between samples with different thermal histories was eliminated. Samples for quenching were then prepared from the remaining annealed disks by placing them one at a time on a $1 \mathrm{~cm}^{2}$ by $0.5 \mathrm{~cm}$ thick, light weight alumina fiber board and then putting them inside a muffle furnace that was already at the desired temperature, ranging from 450 to $800^{\circ} \mathrm{C}$. After a set 20 min soak time, the sample was quickly removed and either dropped onto an alumina sand bed with flowing air or dropped into a stirred silicone oil bath and allowed to cool to room temperature. The cooling rate for an air quenched sample was measured with a pyrolaser to be roughly $15^{\circ} \mathrm{C} / \mathrm{s}$ within the $\Delta T_{r}$. Based on these measurements, cooling rates for the oil quenched glasses were calculated to be more than two orders of magnitude greater than air quenching. After quenching from $550^{\circ} \mathrm{C}$ and higher, the samples exhibited typical birefringence patterns for a quenched glass under cross-polarized light. The faces of the samples were then polished with 800 grit $\mathrm{SiC}$ before platinum electrodes were sputtered on opposite faces 
in a two-electrode configuration. Kerosene or lapping oil was used whenever possible during all stages of sample preparation to minimize any leaching of the alkali from the samples.

In addition to the standard $20 \mathrm{~min}$ soak time, times of 3,5 and $60 \mathrm{~min}$ were also used at the $550^{\circ} \mathrm{C}$ soak temperature followed by quenching in air, as previously described. Every effect was made to minimize the time required for the sample to reach thermal equilibrium in the furnace, however one should realize that this time is not instantaneous and that it took at least 2 min for the furnace to stabilize after inserting the sample. These times to reach equilibrium may not be significant for the longer soak times, but are significant for the shorter times e.g., $3 \mathrm{~min}$ soak, and so should be taken in account when analizing the data.

\subsection{Impedance measurements}

Impedance measurements were made using a Schlumberger SL1260 Impedance/Gain Phase Analyzer between $1 \mathrm{~Hz}$ and $1 \mathrm{MHz}$ in the temperature range of 100 to $250^{\circ} \mathrm{C}$ in $10^{\circ} \mathrm{C}$ increments. This temperature range was chosen to be low enough that no appreciable structural relaxation of the glass would occur during the measurement (total time approximately $20 \mathrm{hrs}$ ) yet high enough that the sample impedance could be measured accurately with this instrument. At room temperature, the impedance of these samples was beyond the upper limit of the effective range of the SL1260. Fifty points per decade of frequency were taken for each sample. Standard corrections to the data were made by subtracting the stored digitized electrical response from the empty and shorted cell at $200^{\circ} \mathrm{C}$. All measurements were made using a $3 \mathrm{~V}$ test signal and a $1 \mathrm{~s}$ time delay between successive points. Up to a $15 \mathrm{~s}$ time integration was used for each point to minimize measurement error. Test specimens were placed in an Inconel cell with spring loaded platinum electrodes and leads. Circular Inconel shields placed near the sample diminished any induced effects from the electrical windings in the furnace. A type $\mathrm{K}$, nickel-chromium versus nickel-aluminum, thermocouple, placed adjacent to the specimen, was used for all sample temperature measurements. The test cell was positioned inside a mullite tube that was open at one end and located inside a clamshell tube furnace. A dry $\mathrm{N}_{2}$ atmosphere was used to ensure the integrity of the electrodes and to reduce water absorption by the specimen. The samples were held for a minimum of $30 \mathrm{~min}$ at each temperature to allow the system to come to thermal 
equilibrium before a measurement was initiated. Variation in the cell temperature was within $\pm 0.2^{\circ} \mathrm{C}$ for the duration of the measurement. By using sputtered platinum electrodes [17], polishing the sample surfaces to 800 grit [17] and using a small test signal [18], electrode polarization effects were reduced to a minimum.

The $\sigma_{\mathrm{dc}}$ for each sample was determined by fitting the measured complex impedance arc to a depressed semicircle using a complex nonlinear least squares curve fitting program. An example of such a fit to the data is shown in Fig. 1. The sample resistivity, $\rho$, is simply the low frequency intercept of the depressed semicircle fit with the real axis. The $\sigma_{\mathrm{dc}}$ is equal to $L / \rho A$, where $A$ is equal to the area of the electrode surface and $L$ is the sample thickness.

\section{Results}

\subsection{Annealed glass}

The $\sigma_{\mathrm{dc}}$ data for the annealed glass (Fig. 2, filled circle) exhibited Arrhenius-type behavior over the temperature range examined:

$$
\sigma_{d \varepsilon}-B \exp \left(-E_{a} / R T\right) \text {, }
$$

where $B$ is a constant, $E_{a}$ is the activation energy for $\sigma_{d c}, R$ is the gas constant and $T$ is the absolute temperature. The $\mathrm{E}_{\mathrm{a}}$ for $\sigma_{\mathrm{dc}}$ for the annealed sample was calculated to be $20.2 \mathrm{Kcal} / \mathrm{mol}$. The density at room temperature for this glass was measured to be $2.307 \mathrm{~g} / \mathrm{cm}^{3}$ by Archimedes technique using lapping oil (density of $0.8663 \mathrm{~g} / \mathrm{cm}^{3}$ ) as the suspension liquid. The glass coefficient of thermal expansion was measured to be $5.70 \times 10^{-6}{ }^{\circ} \mathrm{C}^{-1}$ on a dual pushrod dilatometer using sapphire as a reference standard and employing a $3 \mathrm{~K} / \mathrm{min}$ heating rate. The glass transition temperature was taken from the same dilatometer trace and was measured to be $537^{\circ} \mathrm{C}$. These values were in good agreement with those reported for similar composition in the literature [1920]. Finally, chemical analysis of three samples of the glass showed an average potassium oxide concentration of $10.2 \mathrm{~mol} \%$.

\subsection{Quenched Glasses}

As with the annealed sample, Arrhenius behavior was observed for $\sigma_{\mathrm{dc}}$ for the glasses 
quenched in air (Fig. 2). The variation in $\sigma_{\mathrm{dc}}$ with soak temperature can be better depicted by plotting the $\sigma_{\mathrm{dc}}$ at a fixed measurement temperature for all of the quenched samples as a function of the soak temperature. Fig. 3 (bottom curve) is simply a section through the data of Fig. 2 at a fixed temperature of $150^{\circ} \mathrm{C}$. Relative to the annealed glass, little change in $\sigma_{\mathrm{dc}}$ was observed for soak temperatures below $475^{\circ} \mathrm{C}$. For soak temperatures from 475 to $625^{\circ} \mathrm{C}, \sigma_{\mathrm{dc}}$ increased steadily, resulting in over an order of magnitude higher $\sigma_{\mathrm{dc}}$ for a soak temperature of $600^{\circ} \mathrm{C}$ and higher. For glasses quenched from $625^{\circ} \mathrm{C}$ or above, the $\sigma_{\mathrm{dc}}$ was independent of the soak temperature. Arrhenius behavior was also observed for the glass samples quenched in the silicone oil. The general shape of the conductivity versus soak temperature plot (Fig. 3, top curve) is comparable to the air quench plot, with $\sigma_{\mathrm{dc}}$ independent of the soak temperature for temperatures below $475^{\circ} \mathrm{C}$ followed by a region of rapidly increasing $\sigma_{\mathrm{dc}}$. Where-as $\sigma_{\mathrm{dc}}$ leveled off for soak temperatures of $625^{\circ} \mathrm{C}$ for the air cooled samples, $\sigma_{\mathrm{dc}}$ of the oil quenched samples did not reach a plateau until nearly soak temperatures of $660^{\circ} \mathrm{C}$. The wider range over which $\sigma_{\mathrm{dc}}$ could be changed for the oil-quenched glasses resulted in a maximum value for $\sigma_{\mathrm{dc}}$ of $2.4 \times 10^{-9}(\Omega-\mathrm{cm})^{-1}$ compared to $1.9 \times 10^{-9}(\Omega-\mathrm{cm})^{-1}$ for the air quenched glasses.

\subsection{Relaxation behavior during isothermal soaking}

The $\sigma_{\mathrm{dc}}$ as a function of soak time (Fig. 4) was best fit by the equation:

$$
\sigma_{d c}=c\left[1-\exp (-t / \tau)^{\beta}\right]+d,
$$

where $c$ is equal to the range of values over which $\sigma_{d c}$ changes, $t$ is equal to time, $\tau$ is a time constant, $\beta$ is a constant such that $0<\beta \leq 1$ and $d$ corresponds to $\sigma_{\mathrm{dc}}$ for the annealed glass. This stretched exponential form is consistent with the Kohlrausch-Williams-Watts equation used by Moynihan and others to fit electric field relaxation [21]. The $\sigma_{\mathrm{dc}}$ rose to a maximum after $20 \mathrm{~min}$ at $550^{\circ} \mathrm{C}$ and then leveled off. The longer soak time of $60 \mathrm{~min}$ did not increase the $\sigma_{\mathrm{dc}}$ any further. A value of $\beta=1$ was used in fitting the curve to the data.

\section{Discussion}

The data of $\sigma_{\mathrm{dc}}$ as a function of soak temperature (Fig. 3) can be broken down into three 
separate regions.

- The first region corresponds to temperatures below $T_{1}$, which is $475^{\circ} \mathrm{C}$ and less for this potassium-silicate glass with the previously described thermal histories. At these temperatures, the $\tau$, for this glass composition are so long that the glass structure is frozen and is thus unaffected for the soak time of $20 \mathrm{~min}$ and the two different cooling rates. The $\sigma_{\mathrm{dc}}$ in this first region remains essentially unchanged from that of the annealed glass.

- The second region corresponds to the $\Delta T_{r}$ of the glass and is bounded by the temperature limits of 475 to $625^{\circ} \mathrm{C}$ for the air quenched glass and 475 to $660^{\circ} \mathrm{C}$ for the oil quenched glass. The $\tau_{8}$ of the glass within this temperature region is on the same order of the experimental time scale and so the glass structure is able to relax during the soak. This relaxation from the annealed structure to a structure associated with a higher temperature state results in the rise in $\sigma_{\mathrm{dc}}$. The value reached during the $20 \mathrm{~min}$ soak, which is frozen in during quenching, increased with increasing soak temperature up to $T_{v}$.

- The final region corresponds to temperatures above $\mathrm{T}_{u}$, which is $625^{\circ} \mathrm{C}$ for the air quenched samples and $660^{\circ} \mathrm{C}$ for the oil quenched samples. Above $T_{w}$, the $\tau_{8}$ for this glass composition is so short that the glass can structurally relax faster than it can be quenched. For soak temperatures near or greater than $T_{w}$, the glass apparently attained a state during the $20 \mathrm{~min}$ soak that is higher in $\sigma_{d c}$ than plotted in Fig. 3. However, the glass can relax back to a state that corresponds to $T_{u}$ during quenching, due to the short $\tau_{z}$ associated with these higher soak temperatures. Consequently, the value for $\sigma_{d c}$ remains constant for soak temperatures greater than $\mathrm{T}_{u}$ for a given cooling rate.

The similar shape of the two plots for different cooling rates of the $\sigma_{d c}$ as a function of soak temperature (Fig. 3) can be explained by understanding the relationship between the cooling

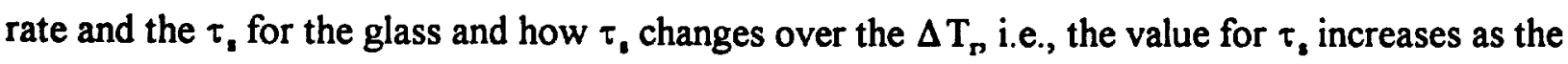


glass temperature increases from $T_{1}$ to $T_{u}$. The use of an increased cooling rate (e.g., oil vs. air quenching) shifts $T_{u}$ to a higher value. This upward shift in $T_{u}$ for increased cooling rates is demonstrated when one compares $\Delta \mathrm{T}_{\mathrm{r}}$ for the air quenched plot to the oil quenched plot in Fig. 3 . The $\sigma_{d c}$ leveled off at a $T_{u}$ limit of approximately $625^{\circ} \mathrm{C}$ for the air quench and $660^{\circ} \mathrm{C}$ for the oil quenched samples, corresponding to a $35^{\circ} \mathrm{C}$ increase in $\Delta T_{r}$. The increase in $\Delta T_{r}$ is due to the faster cooling rate of the oil quenching being able to freeze in glass structures that are affiliated with these higher temperatures and which have corresponding shorter $\tau_{8}$. Above $660^{\circ} \mathrm{C}, \tau_{8}$ is so short that even the faster cooling rate of oil quenching is too slow to freeze the glass structure before it can relax back to the structural state associated with $660^{\circ} \mathrm{C}$. Consequently, quenching from temperatures higher than $T_{u}$ does not effect $\sigma_{d c}$ for a fixed cooling rate.

While changing the cooling rate had significant effects on the value for $T_{u}$, the value for $T_{1}$ appeared to remain nearly constant. At these lower temperatures, the mean value for $\tau_{2}$ is on the same order as the soak time for the temperature region just above $T_{1}$ and quickly increases to several hours and longer for temperatures below $T_{1}$. The lack of $\sigma_{d c}$ dependence on soak temperature for soaks below $T_{1}$ is due to the extended $\tau_{1}$ associated with these temperatures. Little structural change occurred in the glass during soaks at or below $475^{\circ} \mathrm{C}$, regardless of the means of quenching used to cool the samples back down to room temperature. Only a controlled cooling rate that was on the same order of the $\tau_{\mathrm{g}}$ in this region would allow the glass structure to change enough to result in a change in $T_{1}$. In fact, the cooling rate does not affect the shape of $\sigma_{\mathrm{dc}}(T)$ for soak temperatures below $575^{\circ} \mathrm{C}$. In this region, the shape of the $\Delta T_{r}$ is dominated more by the soak time and less by the cooling rate.

The results of varying the soak time at $550^{\circ} \mathrm{C}$ (Fig. 4) show that the $\sigma_{d c}$ was unaffected by soak times longer than $20 \mathrm{~min}$. By this time, the glass structure was at metastable equilibrium at this temperature and so $\sigma_{\mathrm{dc}}$ remained constant. Soak times of 3 and $5 \mathrm{~min}$ have $\sigma_{\mathrm{dc}}$ that are significantly less than the 20 min value but are still greater than that measured for the annealed glass. For these soak times, the glass has not yet reached a structural state that is in equilibrium with the glass temperature and so $\sigma_{\mathrm{dc}}$ is still increasing as the glass structure changes with time. If it is assumed that $\tau$ in Eq. 2 corresponds to $\tau_{s}$, the average value for $\tau_{1}$ at $550^{\circ} \mathrm{C}$ was $7.3 \mathrm{~min}$. With increasing soak temperature, these times for $\tau$, will decrease until they become comparable 
to the cooling rate at $T_{u}$ and $\sigma_{d c}$ will become independent of soak temperature. As the soak temperature decreases from $550^{\circ} \mathrm{C}$ to $T_{b}, \tau_{s}$ will increase until it is greater than the soak time of 20 $\min$. For temperatures below $T_{1}$, the glass structure relaxes at such a slow rate that $\sigma_{d c}$ is unaffected by any small changes that occur in the $20 \mathrm{~min}$ soak time.

Further work, currently in progress and to be presented at a later date, includes: 1) study of cooling rate in different quench media, 2) effect of soak/quench conditions on $E_{2}, 3$ ) significance of best curve fit to Fig. 3, and 4) density versus both soak time and soak temperature.

\section{Conclusion}

A simple technique for measuring and depicting the $\Delta T_{r}$ has been demonstrated from $\sigma_{d c}$ results. The $\Delta T_{r}$ can be broken down into three main regions, which have been explained in terms of the $\tau_{1}$ as a function of the soak temperature. Measurement of $\tau$ (equation 2) at $550^{\circ} \mathrm{C}$ found it to be equal to $7.3 \mathrm{~min}$, which was consistent with the times associated with $\tau_{\mathrm{a}}$ in this temperature region. This supports the conclusion that $T_{1}$ is controlled by the soak time since $\tau_{8}$ is of the same order at $T_{1}$. By the same manner, since $T_{u}$ is controlled by the cooling rate, $\tau$, should roughly correspond to the same time scale as the cooling rate.

\section{References}

[1] K.M. Davis and M. Tomozawa, J. Non-Cryst. Solids 185 (1995) 203.

[2] S. Brawer, Relaxation in Viscous Liquids and Glasses, (American Ceramic Society, Columbus, OH, 1985) p. 38.

[3] H.N. Ritland, J. Am. Ceram. Soc. 37 (1954) 370.

[4] A. Winter, J. Am. Ceram. Soc. 26 [6] (1943) 189.

[5] L.P. Boesch and C.T. Moynihan, J. Non-Cryst. Solids 17 (1975) 44.

[6] M. Yoshiyagawa, Masters Thesis, Rensselaer Polytechnic Inst., 1982.

[7] M. Yoshiyagawa and M. Tomozawa, J. De Physique, Colloque C9, supplement au n ${ }^{\circ} 12$, Tome 43 (1982) C9-411.

[8] P.W. Angel, R.E. Hann and A.R. Cooper, J. Non-Cryst. Solids 183 (1995) 277.

[9] H.N. Ritland, J. Am. Ceram. Soc. 37 (1954) 370.

[10] U.E. Schnaus, C.T. Moynihan, R.W. Gammon and P.B. Macedo, Phys. Chem. Glasses 11 (1970) 213.

[11] J. A. McMillan, J. Chem. Phys. 42 (1965) 3497.

[12] B. Wunderlich, D.M. Bodily and M.H. Kaplan, J. Appl. Phys. 35 (1964) 95.

[13] C.T. Moynihan, A.J. Easteal, J. Wilder and J. Tucker, J. Phys. Chem. 78 (1974) 262673.

[14] S.M. Wolpert, A. Weitz and B. Wunderlich, J. Polym. Sci. Part A-2, 9 (1971) 1887. 
[15] S.M. Rekhson and G.W. Scherer, J. Phys. C9 (1982) 427.

[16] R.J. Charles, Phys. Chem. Glasses 10 (1969) 169.

[17] C. Kim and M. Tomozawa, J. Am. Ceram. Soc. 59 (1976) 127.

[18] J.R. Macdonald, J. Appl. Phys. 44 [8] (1973) 3455.

[19] O.V. Mazurin, M.V. Streltsina and T.P. Shvaiko-shvaikovskaya, Handbook of Glass Data, Part A: Silica Glass and Binary Silicate Glasses, (Elsevier, New York, 1983) p. 215.

[20] N.P. Bansal and R.H. Doremus, Handbook of Glass Properties, (Academic Press, New York 1986) p. 54.

[21] C.T. Moynihan, L.P. Boesch and N.L. Laberge, Phys. Chem. Glasses 14 (1973) 6122. 


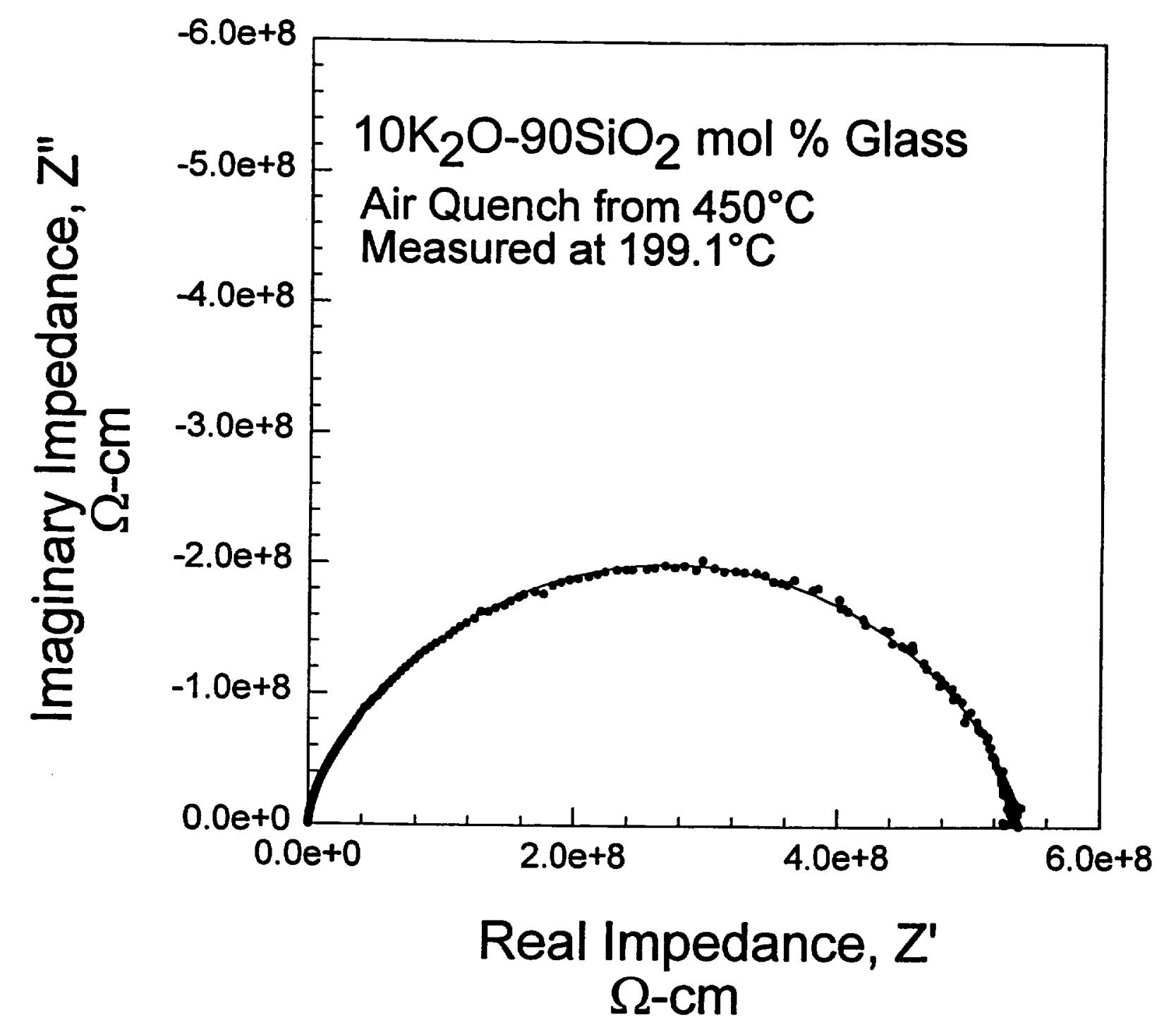

Figure 1.-Plot of the complex impedance at $199.1^{\circ} \mathrm{C}$ of the $10 \mathrm{~K}_{2} \mathrm{O}-90 \mathrm{SiO}_{2} \mathrm{~mol} \%$ glass quenched in air from $450^{\circ} \mathrm{C}$. The solid line corresponds to a least-squares semicircular fit and the low frequency (frequency decreases from left to right) $x$-axis intercept is equal to the resistivity of the sample. 


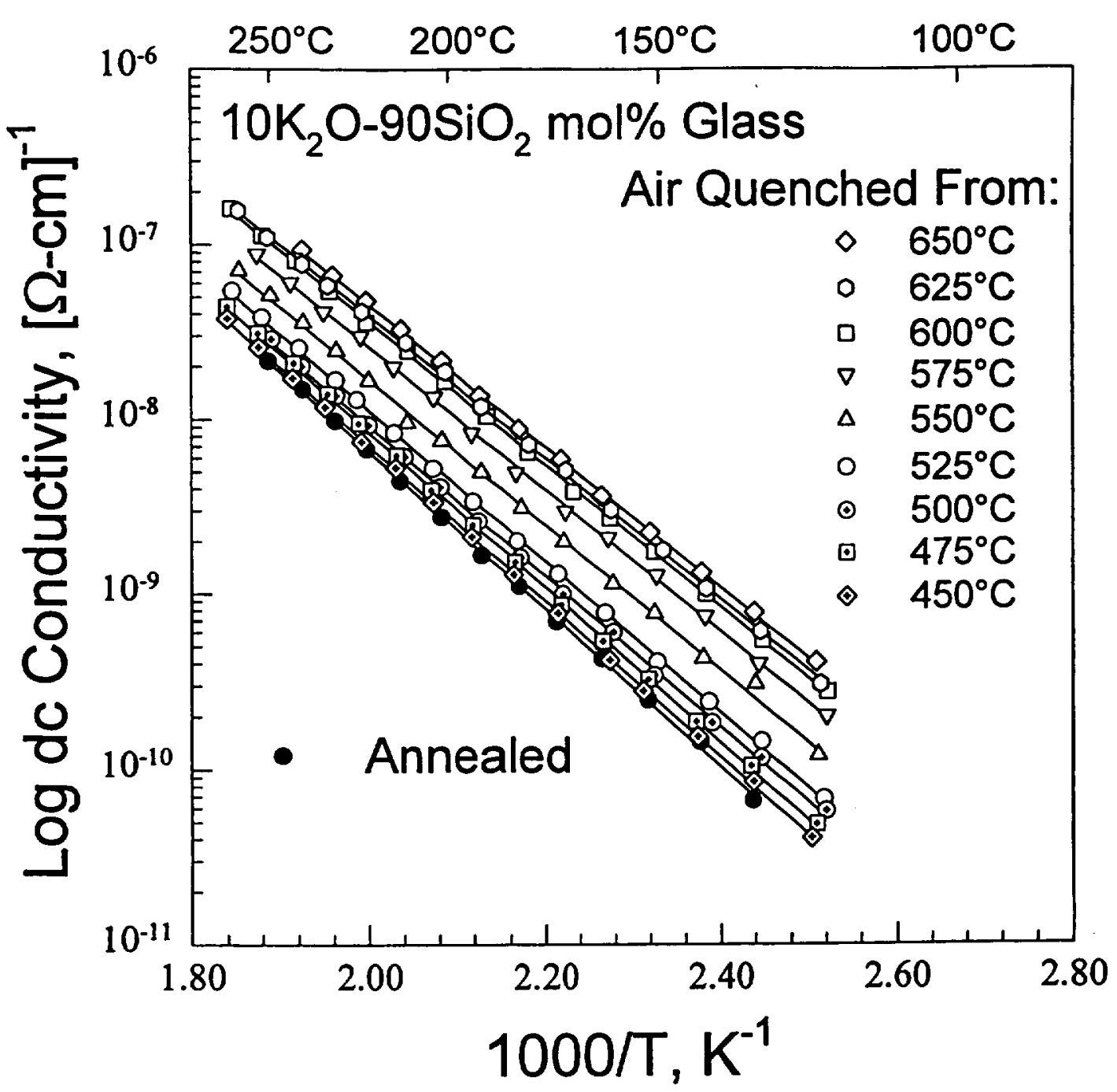

Figure 2.-Log of $\sigma_{\mathrm{dc}}$ against $1 / \mathrm{T}$ for the glasses soaked for $20 \mathrm{~min}$ at 450 to $650{ }^{\circ} \mathrm{C}$ and quenched in air. 


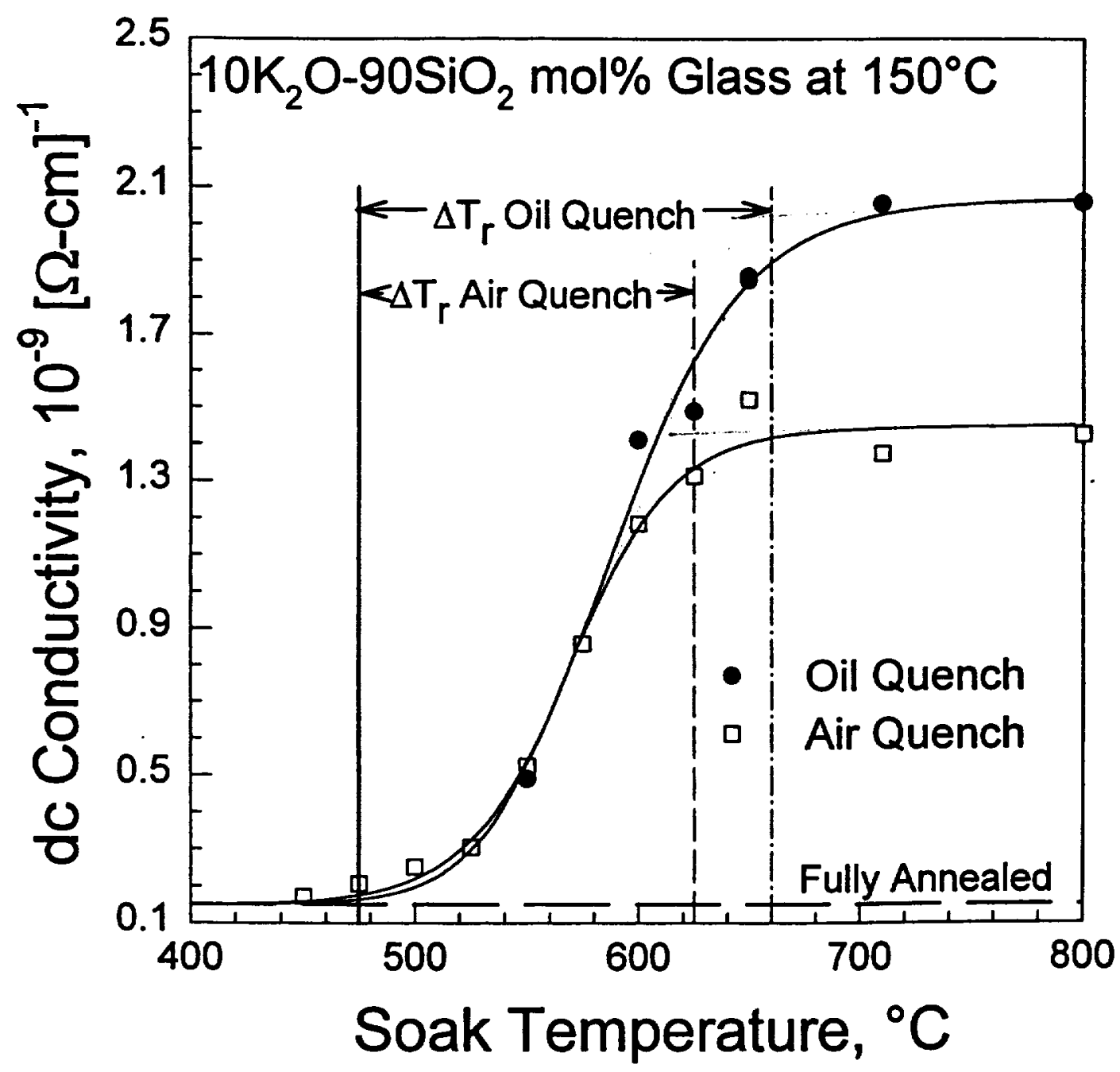

14

Figure 3.-The $\sigma_{\mathrm{dc}}$ at $150^{\circ} \mathrm{C}$ as a function of the soak temperature for the air and oil quenched glasses. 


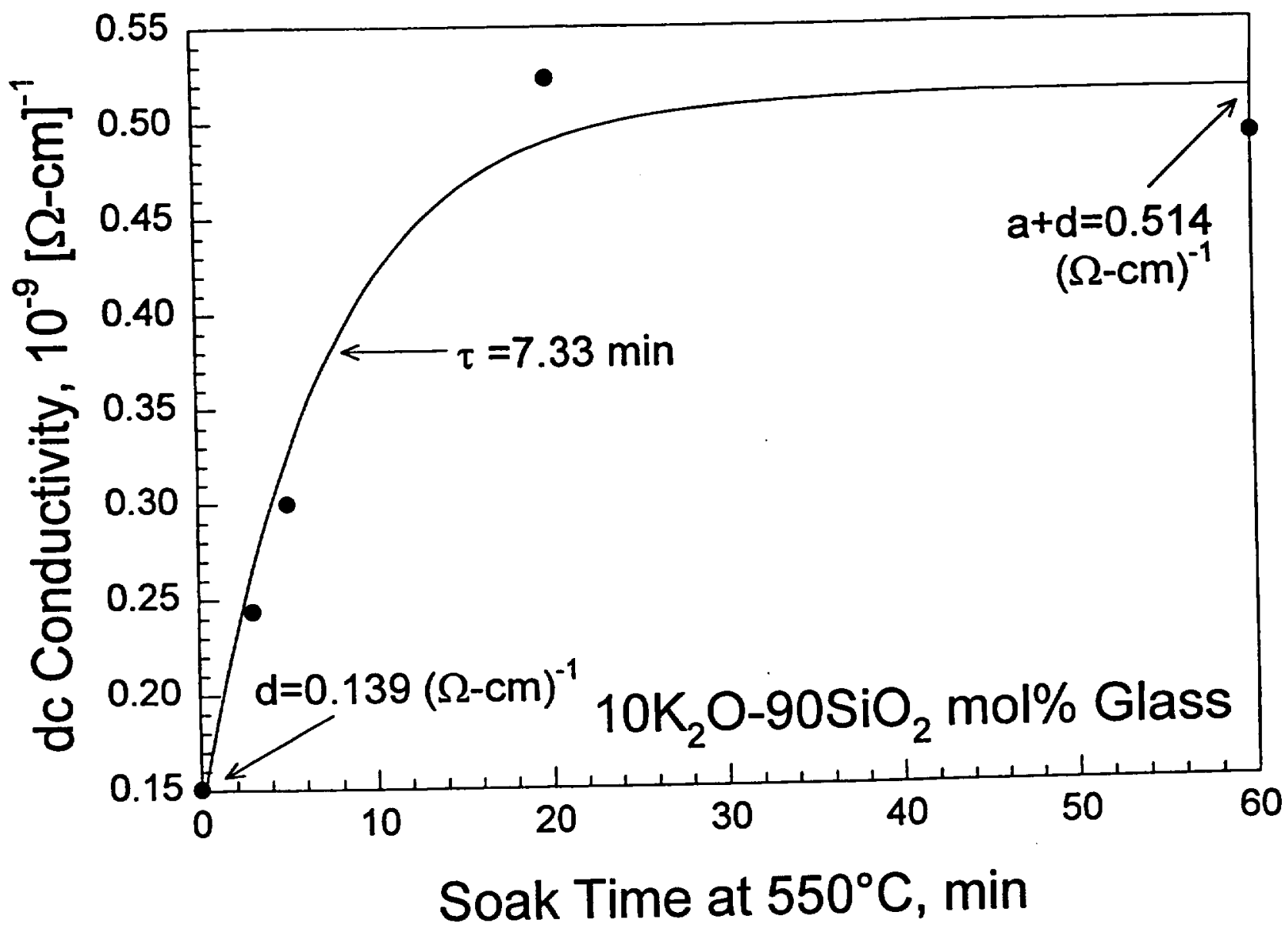

Figure 4.-The $\sigma_{\mathrm{dc}}$ at $550^{\circ} \mathrm{C}$ as a function of the soak time. Data was fit to Eq. (2). 


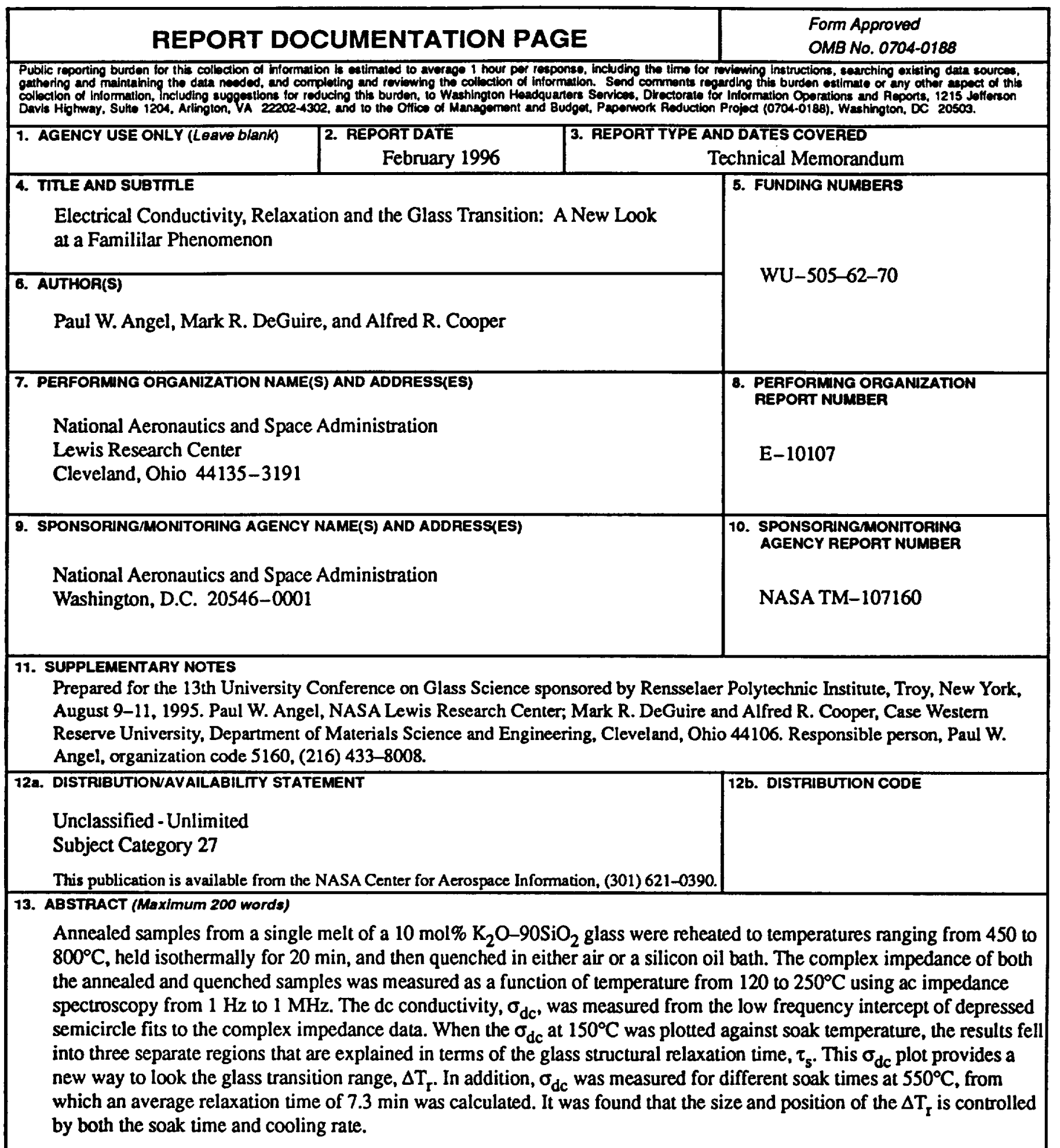


National Aeronautics and

Space Administration

Lewis Research Center

21000 Brookpark Rd.

Cleveland, OH 44135-3191

Ontelal Bualnose

Penally for Pivato Uao $\$ 300$

POSTMASTER: II Undellverable - Do Nol Return 